\title{
Vibration Method for Elastic Modulus of Glued Laminated Beams
}

\author{
Ling-ling $\mathrm{Yu}^{1, \mathrm{a}}$, Jiejun Wang ${ }^{1, \mathrm{~b}}$ Diyang $\mathrm{Xia}^{1, \mathrm{c}}$ \\ ${ }^{1}$ College of Civil Engineering and Mechanics, \\ Central South University of Forestry and Technology, Changsha 410004, P.R.China

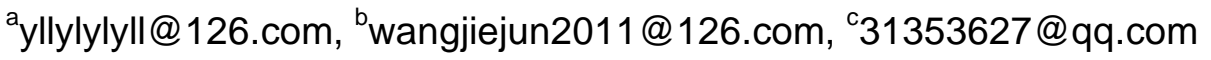

Keywords: Vibration method; Glued laminated beams; Elastic modulus; Natural frequency, Static load testing.

\begin{abstract}
In order to study basic method for measuring elastic modulus of glued laminated beams using vibration method, the theoretical basis of measurement was introduced. A forced vibration method was used to measure the natural frequency of glued laminated beams in simple supported condition. Compared with traditional finite element method and static load test method, the elastic modulus of glued laminated beams tested by vibration method is feasible.
\end{abstract}

\section{Introduction}

Glued laminated timber, or glulam, is a highly innovative construction material. Glulam is stronger than steel and has greater strength and stiffness than comparably sized dimensional lumber. Glulam is a stress-rated engineered wood beam composed of wood laminations, which are bonded together with durable, moisture-resistant structural adhesives. Glulam is the most cost effective engineered wood production on the market today making it the best choice for floor, roof and wall framing. The modulus of elasticity $\mathrm{E}$ is an important index for weighing the physical property of wood. In practical use, the modulus of elasticity and loss of materials is very important for the study of the use, modification and microstructure of material. In the non-destructive check for material, the dynamic elastic modulus and the change of loss are also important indexes for judging if there is defect in the materials [1]. Except the standard static force method, study also adopts the dynamic method of measuring its natural frequency to measure the dynamic elastic modulus of material.

\section{Material and Production Method}

The glued laminated beams in this thesis were composed of Xingan Larch single plate beams. The nominal sizes of the lamination cross-section were $30 \mathrm{~mm}$ in thickness, $150 \mathrm{~mm}$ in width and $2100 \mathrm{~mm}$ in length, the average density is $0.55 \mathrm{~g} / \mathrm{cm}^{3}$, the average moisture content is 13 percent. The appearance grade of Larch used in this test is Id, the structural adhesive is water-based polyurethane (mass ratio of polyurethane to curing agent $=100: 15-20$ ). The test specimens are produced in three forms: single board, two layers and three layers of glued laminated timber. In order to measure its magnitude and weight, the vernier and analytical balance are used, the detailed result is in table 1.

Table 1 Quality and dimensions of test specimens

\begin{tabular}{cccccc}
\hline layers & numbers & $\begin{array}{c}\text { average quality } \\
(\mathrm{kg})\end{array}$ & $\begin{array}{c}\text { average length } \\
(\mathrm{m})\end{array}$ & $\begin{array}{c}\text { average width } \\
(\mathrm{m})\end{array}$ & $\begin{array}{c}\text { average height } \\
(\mathrm{m})\end{array}$ \\
\hline 1 & 12 & 6.44 & 2.094 & 0.151 & 0.031 \\
2 & 12 & 13.81 & 2.095 & 0.149 & 0.063 \\
3 & 6 & 20.06 & 2.094 & 0.150 & 0.095 \\
\hline
\end{tabular}




\section{Basic Principles and Test Methods}

Vibration Test Method A vibration technique was used to identify the first bending mode frequency of the beam. This method is a purely time domain method and was proposed because it eliminates the need for modal analysis. Let us consider a uniform prismatic beam of length $\mathrm{L}$, height $\mathrm{h}$ and width w. Strength of materials hypotheses are applied $[2,3]$, The fundamental natural frequency of a structural system is related to its stiffness by the following equation (1):

$$
E I=\frac{f^{2} W L^{3}}{2.46 g}
$$

Where $\mathrm{E}$ is dynamic modulus of elasticity $(\mathrm{Pa})$,

f fundamental natural frequency $(\mathrm{Hz})$,

W beam weight $(\mathrm{kg} \cdot \mathrm{g})$,

$\mathrm{L}$ beam span $(\mathrm{m})$,

I beam moment of inertia $\left(\mathrm{m}^{4}\right)$, and

$\mathrm{g}$ acceleration due to gravity $\left(9.8 \mathrm{~m} / \mathrm{s}^{2}\right)$.

Equation (1) is derived from the characteristic equation of motion of a vibrating beam. The constant, 2.46, is based on boundary conditions for simply supported beams. Although Equation (1) represents an idealized system, its use for estimating the modulus of elasticity of lumber is widely recognized. The vibration and dynamic signal collecting system used in this thesis is JMM-268 Dynamic Measuring Instrument, made in Changsha Kingmach Hightechnics Co.,Ltd. The different glulams were built at Structural Laboratory at Central South University of Forestry and Technology. The calculation of beam span is 2 meters. One end is fixed with hinge bearing, the other end is a movable hinge support. The metrical principium is that fixing the acceleration sensor at the midspan, vibration of the beam system was initiated by an impact from a hammer. The free vibration response was measured and collected by Dynamic Measuring Instrument. Then, the first natural frequency of simply supported beam fl can be calculated and the $\mathrm{E}$ also can be reckoned.

Vibration Analysis of Fnite Element Method The frequency equation of free vibration analysis of structures by the finite element method can be expressed by the following:

$\left|[K]-\omega^{2}[M]\right|=0$

In Equation (2),

$[\mathrm{K}]$ is the stiffness matrix,

$[\mathrm{M}]$ is the mass matrix,

$\omega$ is the angular frequency (radians per second).

Wood is an orthotropic material with unique and independent properties in different directions, So glued laminated beam is an anisotropic material. In this paper, the beam will be simplified for transversely isotropic material. The software used in this paper is the Large Finite Element Analyze Software Midas Civil. By using the beam element, the simply supported beam is divided into 22 units in accordance with section properties. A lumped mass $(553.5 \mathrm{~g})$ is applied to the midspan to simulate the quality of the acceleration sensor. The material properties of larch glulam beams are shown in table 2 .

Table 2 The material properties of larch glulam beams

\begin{tabular}{cccccc}
\hline $\begin{array}{c}E_{x} \\
(\mathrm{MPa})\end{array}$ & $\begin{array}{c}E_{z} \\
(\mathrm{MPa})\end{array}$ & $\mu_{x z}$ & $\mu_{y z}$ & $\begin{array}{c}G_{x z} \\
(\mathrm{MPa})\end{array}$ & $\begin{array}{c}G_{y z} \\
(\mathrm{MPa})\end{array}$ \\
\hline 14480 & 830 & 0.53 & 0.63 & 535.4 & 66 \\
\hline
\end{tabular}

Notation: $E_{x}$ is the longitudinal modulus of elasticity, $E_{z}$ is the transverse modulus of elasticity, $\mu_{x z}, \mu_{y z}$ are Poisson's ratios, $G_{x z}, G_{y z}$ represent shear Modulus.

Static Load Testing Measuring modulus of elasticity of a structure by static bending techniques is the foundation of machine stress rating of lumber [4]. In three points bending test method, the modulus 
of elasticity is determined using the classical equations of strength of materials applied to straight beams. Utilizing the load-deflection relationship of a simply supported beam loaded at its midspan. Modulus of elasticity can be computed directly by using equations derived from fundamental mechanics of materials. The modulus of elasticity is:

$$
E_{s}=\frac{l^{3} \Delta F}{48 I \Delta \delta}
$$

Where $E_{s}$ is bending modulus of elasticity by static loading test,

$l$ length between the two supports,

$\Delta F$ static load increment,

$\Delta \delta$ deflection increment.

In this paper, the $l$ is 2 meters in length. The deflection value of midpoint is measured by dial gauge, which is placed below the midpoint of beam. Loads applied to single board, two layers and three layers of glued laminated timber are $0.2 \mathrm{KN}, 0.3 \mathrm{KN}$ and $0.5 \mathrm{KN}$ respectively.

\section{Results and Discussion}

Comparison and Analysis of Frequency between Measured and Theoretical Value The first bending mode frequency of glulam measured by vibration method was obtained (Table 3 ). Each test specimen was struck 15 times, 10 reasonable data were chosen to compute the average value. Using the structural vibration analysis method and Finite Element Analyze Software Midas Civil, the fundamental frequency of simply sopported beam was calculated (Table 4). In the progress of calculation, geometry and mass density of the beam were measured.

Table 3. Measured natural frequency

\begin{tabular}{|c|c|c|c|c|c|}
\hline layers & number & $\begin{array}{l}\text { Maximun value } \\
\qquad(\mathrm{Hz})\end{array}$ & $\begin{array}{c}\text { Minimum value } \\
\qquad(\mathrm{Hz})\end{array}$ & $\begin{array}{c}\text { Average value } \\
(\mathrm{Hz})\end{array}$ & Variance \\
\hline 1 & 6 & 15.71 & 14.00 & 14.73 & 0.39 \\
\hline 2 & 12 & 33.62 & 28.66 & 30.99 & 3.35 \\
\hline 3 & 6 & 47.33 & 42.34 & 44.77 & 3.70 \\
\hline \multicolumn{6}{|c|}{ Table 4. Theoretical natural frequency } \\
\hline layers & number & $\begin{array}{l}\text { Maximun value } \\
\qquad(\mathrm{Hz})\end{array}$ & $\begin{array}{c}\text { Minimum value } \\
(\mathrm{Hz})\end{array}$ & $\begin{array}{c}\text { Average value } \\
(\mathrm{Hz})\end{array}$ & Variance \\
\hline 1 & 6 & 16.02 & 14.86 & 15.54 & 0.19 \\
\hline 2 & 12 & 32.46 & 29.76 & 31.15 & 0.80 \\
\hline 3 & 6 & 50.26 & 47.51 & 48.81 & 1.41 \\
\hline
\end{tabular}

The theoretical variance values are $0.19,0.80$ and 1.41 . The reason is that the natural frequency is affected by changing in stiffness and load sharing. The measured variance values are $0.39,3.35$ and 3.70, which is larger than the theoretical variance respectively. This indicated that in addition to the size and quality of wood, the material itself also has certain difference. For the same component: error $=$ (theoretical value - measured value) / theoretical value. The average error of single board, two layers and three layers of glued laminated timber is $5.19 \%, 1.14 \%$ and $6.76 \%$ respectively. The measured value is less than the theoretical value, the maximum difference is less than $10 \%$, which reflects the accuracy of vibration test method is better.

Comparison of elastic modulus between vibration and static test method The dynamic elastic modulus $E_{d}$ can be gotten by Eq.1, as the static elastic modulus $E_{s}$ can be gotten by Eq.3. The results are shown in Table 5. 
Table 5 Comparison of elastic modulus between vibration and static test method

\begin{tabular}{cccccccccc}
\hline layers & number & $\begin{array}{c}\text { Maximum value } \\
(\mathrm{GPa})\end{array}$ & \multicolumn{2}{c}{$\begin{array}{c}\text { Minimum value } \\
(\mathrm{GPa})\end{array}$} & \multicolumn{2}{c}{$\begin{array}{c}\text { Average value } \\
(\mathrm{GPa})\end{array}$} & Variance \\
\cline { 2 - 11 } & & $E_{d \max }$ & $E_{\text {smax }}$ & $E_{\text {dmin }}$ & $E_{\text {smin }}$ & $\bar{E}_{d}$ & $\bar{E}_{s}$ & $\sigma_{d}$ & $\sigma_{s}$ \\
\hline 1 & 6 & 12.11 & 13.79 & 9.81 & 10.83 & 11.06 & 12.72 & 0.69 & 3.18 \\
2 & 12 & 15.36 & 16.81 & 10.36 & 11.74 & 13.26 & 14.51 & 2.34 & 2.30 \\
3 & 6 & 12.98 & 11.63 & 10.81 & 10.76 & 11.48 & 11.21 & 0.65 & 0.21 \\
\hline
\end{tabular}

Table 5 compares measured elastic modulus from vibration test method and static test method. It shows that under laboratory conditions, vibration test results are smaller than static method results for single board, two layers glulam, while vibration test results are bigger than static method results for three layers glulam. This is because the quality of the acceleration sensor will decrease the vibration frequency of simply supported beam, which leads to the dynamic elastic modulus results being slightly smaller. For three layers glulam, the quality of the sensor compared to the total beam is small, therefore, the dynamic elastic modulus value is close to the static elasticity modulus value.

\section{Summary}

Glued laminated beam is an anisotropic material, material difference or production process will have a certain influence on the elastic modulus of wood. Vibration method for elastic modulus of glued laminated beams, the measured value is less than the theoretical value, the maximum difference is less than $10 \%$, which reflects the accuracy of vibration test method can satisfy the need of Engineering testing. Vibration method is quick, simple and convenient. The quality of acceleration sensor has a certain influence on the testing results of elastic modulus of glulam beams. Reducing the quality of sensor and increasing the quality of test component, can reduce the test error.

\section{Acknowledgements}

This work was financially supported by Research item of National Forestry Bureau (201304504-3), and the Civil Engineering PhD Teachers' quality Improvement Plan Foundation (2013ZDXK002) of the College of Civil Engineering and Mechanics, Central South University of Forestry and Technology.

\section{References}

[1] Wang Zheng. Yang Xiaojun, Wang Xiwei, et al. Dynamic Test for Elastic Modulus and Damp Ratio of Three Layers Plywood. 2012 International Conference on Affective Computing and Intelligent Interaction Lecture Note in Information Technology, 2012.

[2] L.Brancheriau, H. Bailleres, Natural vibration analysis of clear wooden beams: a theoretical review. Wood Science and Technology, 36(2002) 347-365.

[3] Zhiyong Cai, Robert J. Ross, Michael O. Hunt and Lawrence A. Soltis, Pilot study to examine use of transverse vibration nondestructive evaluation for assessing floor systems. Forest Products Journal 52(1):89-93.

[4]P Robert J.Ross, Roy F. Pellerin, Nondestructive testing for assessing wood members in structures: A review. Gen. Tech. Rep. FPL-GTR-70(Rev.). Madison, WI: U.S. Department of Agriculture, Forest Service, Forest Products Laboratory. 2-3.

[5] Fook Choon Choi, Jianchun Li, Bijan Samali, Keith Crews, An Experimental Study on Damage Detection of Structures Using a Timber Beam, Journal of Mechanical Science and Technology 21(2007) 903-907. 